\title{
Economic crisis on public health
}

by

\author{
Buziarsist $\mathrm{J}^{1,2}$
}

It is now obvious, in Belgium as in other industrialised countries that the economy has entered into a recession. This crisis has occurred in a context that WHO judges alarming. The last report of WHO denounces inequalities in access to care during this time of recession (1). WHO is concerned about the impact of the crisis on people's health. Margaret Chan, Director-General of $\mathrm{WHO}$, said that it would not be surprising to observe an increase in the prevalence of stress, suicide and mental disorders (speech of the twenty-third Forum on Global Issues Berlin Germany, 18 March 2009). Yet, some economic studies conducted during previous periods of crisis nuance alarmist generated results showing that recession might have a positive impact on the health of the populations.

Could the economic crisis be good for your health?

Surprisingly, the loss of income caused by an economic crisis may have beneficial effects on health in the short term. Indeed, some studies have found that for instance if people have more time and less money, they tend to smoke less, exercise more and prepare their own meals. Christopher Ruhm, an economist, published an article in 2000 (2) where he presents a historical analysis of the 1970s and 1980s. He demonstrates that in the United States, the periods of recession are associated with a significant reduction in mortality except mortality from suicide. Emile Durkheim, a French sociologist, has also found that suicide increases during difficult economic conditions (3).

These results can be explained by the 'inhibition effect'. This effect has been attributed to attempts by those who fear job loss to become more like the ideal employee. Accident trauma, particularly that in the workplace, may also decrease in times of reduced production. Therefore, it could be that the recession induces increased morbidity and mortality among the unemployed, but reduces risk taking and, therefore, morbidity and mortality among those who remain employed (4).

Another recent study by Stuckler et al. (5) demonstrated that an increase in unemployment is associated with a significant short-term increase in premature deaths from intentional violence, while reducing traffic fatalities. Active labour market programmes that keep and reintegrate workers in jobs could mitigate some adverse health effects of economic downturns.

\footnotetext{
1 Belgian Association of Public Health, Brussels, Belgium

2 Scientific Institute of Public Health, Brussels, Belgium

Correspondence: jamila.buziarsist@iph.fgov.be
} 
However, even if some beneficial effects could be detected in the short term, the impact of the economic crisis with its sustained insecurity, and declining revenues will be critical in the long term, particularly for the poorest social strata. During such times, access to quality care and a healthy diet are essential. And also, in the longer term, non-adherence to medical treatment could result in increased prevalence of disease, complications of chronic conditions and drug resistance.

The economic crisis may have an impact on antiretroviral treatment too. The results of the UNAIDS survey (6) concerning the impact of the economic crisis on the care and antiretroviral prevention (March 2009) show that eight out of 71 countries report that an impact has already been felt. A further 22 countries expect repercussions during the coming year.

This economic crisis has set in and now preoccupies most people! Health ministers and experts met in Oslo (Norway) in April 2009 to find solutions to the economic crisis that do not threaten the health goals, despite budgetary constraints. Some countries, such as Belgium, Estonia, Hungary, Latvia, Lithuania, Portugal, the Czech Republic and Slovakia, have announced budget revisions (Copenhagen and Oslo, 2 April 2009).

The EU has issued recommendations to regularly monitor the impact of the economic crisis; and to ensure health and long-term care. A meeting of the ECDC (Stockholm) took place in May 2009 to discuss the 'Public Health Response to 2009-2010 Socio-economic Crises'. The coordinator was Constantino Sakellarides (EUPHA President).

The main objectives were to discuss a 'Public Health Framework' for responding to the economic crisis of 2009-2010 following the recommendations of the WHO/EURO meeting on this subject on 1 and 2 April 2009; to exchange experiences on European Public Health response to the socio-economic crises including a focus on communicable diseases and related health determinants and burden of disease; to prepare a 'discussion paper' for a follow-up workshop to be held during the 2009 EUPHA conference. The participants were representatives of 20 selected national public health associations, representatives of EUPHA, representatives of ECDC, WHO and the European Observatory on Health Systems and Policies.

In Belgium, it is currently difficult to assess the impact of the economic crisis on public health. Perhaps the results of the national health survey (7) (general population study carried out every four years) will show us the impact this economic crisis has on the health of the general population. 


\section{References}

1. OMS, les soins de santé primaires : maintenant plus que jamais », OMS, Rapport sur la santé dans le monde 2008

2. Ruhm CJ. Are Recessions Good For Your Health? Q J Econ 2000; 115(2): 617-50

3. Durkheim E. Le suicide. Étude de sociologie (1897). Paris: Les Presses universitaires de France, deuxième édition, 1967, 462 pp.

4. Catalano R, Bellows B. Commentary: if economic expansion threatens public Heath, should epidemiologists recommend recession? Int J Epidemiol 2005; 34(6): 1212-3

5. Stuckler D, Basu S, Suhrcke M, Coutts A, McKee M. The public health effect of economic crises and alternative policy responses in Europe: an empirical analysis. Lancet 2009 ; 374(9686): 315-23

6. Onusida. La crise économique mondiale et les programmes de prévention et de traitements du VIH, vulnérabilité, impact. Genève. Juin 2009

7. http://www.iph.fgov.be/epidemio/epifr/index4.htm 